\title{
Short communication: Characterization of microflora in Mexican Chihuahua cheese
}

\author{
J. A. Renye Jr., ${ }^{1}$ G. A. Somkuti, ${ }^{*}$ D. L. Van Hekken, ${ }^{*}$ and V. M. Guerrero Prieto† \\ *USDA, Agricultural Research Service, Eastern Regional Research Center, Dairy and Functional Foods Research Unit, 600 E. Mermaid Lane, \\ Wyndmoor, PA 19038 \\ †Centro de Investigacion en Alimentacion y Desarrollo, Cuauhtemoc, Chihuahua, Mexico, CP 31570
}

\section{ABSTRACT}

This work was performed to identify the bacterial species present in 10 Chihuahua cheeses obtained from commercial producers in Mexico using 16S rRNA gene analysis. As expected, some of the agar media initially used for isolation were not very selective, supporting the growth of several unrelated bacterial species. Sequence analysis identified potential pathogens, including Escherichia coli and Staphylococcus aureus, in all raw milk samples and 2 pasteurized milk samples. Streptococcus thermophilus and Lactococcus lactis ssp. lactis were identified in 9 and 6 samples, respectively, and would serve as acidifying agents during cheese production. Lactobacilli were identified in all cheeses, with the most prevalent being Lactobacillus plantarum identified in 7 raw milk and 1 pasteurized milk cheeses. Leuconostoc mesenteroides and Streptococcus macedonicus were identified in 4 raw milk cheeses and both were present in all pasteurized milk samples, suggesting that they may play a role in the development of traditional Chihuahua cheese attributes.

Key words: cheese microflora, lactic acid bacteria, artisanal cheese

\section{Short Communication}

The popularity of authentic Hispanic-style cuisine has continued to grow with the increasing Hispanic population in the United States. Essential to many of these dishes are Hispanic-style cheeses, which possess unique quality, flavor, and functional properties (Van Hekken and Farkye, 2003). Traditionally, many of these cheeses have been made using raw milk and are meant to be consumed within 1 mo of manufacture, meaning

\footnotetext{
Received January 14, 2011.

Accepted March 8, 2011.

${ }^{1}$ Mention of trade names or commercial products in this publication is solely for the purpose of providing specific information and does not imply recommendation or endorsement by the US Department of Agriculture.

${ }^{2}$ Corresponding author: john.renye@ars.usda.gov
}

they do not meet US standards, which require all raw milk cheeses be cured for a minimum of $60 \mathrm{~d}$ before distribution (Code of Federal Regulations, 2004). In light of this, demand exists for Hispanic-style cheeses that are made using pasteurized milk and defined starter cultures while maintaining the traditional organoleptic qualities of the cheeses.

Chihuahua cheese, or queso Menonita, is a semi-hard cheese produced using bovine milk in Mennonite communities located in the northern Mexican state of Chihuahua. The cheese has a crumbly texture and is characterized by a tangy flavor that distinguishes it from Cheddar (Kosikowski and Mistry, 1997). More recently, rheological (Van Hekken et al., 2007), compositional (Tunick et al., 2008), and sensory (Van Hekken et al., 2006) analyses were performed on 14 brands of Chihuahua cheese obtained from different commercial cheese plants throughout the state of Chihuahua, Mexico. Of the 14 brands studied, 9 were made using raw milk $(\mathbf{R M})$ and 5 using pasteurized milk (PM) and specific starter cultures. Compositional analysis showed that variation in the make procedures did not significantly affect the composition of the cheese; however, slightly higher levels of casein fragments were observed in the RM cheeses (Tunick et al., 2008). Sensory analysis identified salty, sour, diacetyl, cooked, whey, bitter, and milk-fat as the predominant flavor attributes in the cheeses, with the RM cheeses having higher sour, bitter, and prickle scores (Van Hekken et al., 2006). Sensory analysis also identified 10 of the cheese samples as being closely clustered with respect to flavor scores. These samples were selected for microbiological analysis to identify the bacterial species that may contribute to the organoleptic qualities of the cheeses.

Most of the microbiological analyses performed on Mexican cheeses, including Chihuahua cheese, have focused on the detection and survival of bacterial pathogens (Diaz-Cinco et al., 1992; Saltijeral et al., 1999; Solano-López and Hernández-Sánchez, 2000). Although the 14 brands of Chihuahua cheese were confirmed to be free of Listeria monocytogenes, Escherichia coli O157:H7, enterotoxin-producing Staphylococcus au- 
reus, and Campylobacter spp. before sensory analysis, all cheese samples possessed total aerobic bacterial counts greater than the $5.7 \log _{10} \mathrm{cfu} / \mathrm{g}$ recommended in Mexican cheese standards (Secretaria de Salud-Mexico, 1994). A more detailed analysis of the bacterial species present in the 10 cheese samples closely clustered by sensory attributes was done using selective agar (Bricker et al., 2005). The results of that study showed that mesophilic and thermophilic streptococci and lactobacilli are the predominant bacterial types present in both the RM and PM cheeses. Presumptive leuconostoc species, based on resistance to vancomycin, were also present in high numbers except in one PM cheese. Bacterial isolates were not recovered from all PM cheeses on violet red bile agar (VRB), Baird-Parker agar supplemented with egg yolk tellurite (BP), or kanamycin esculin azide (KEA) agar, suggesting that coliforms, staphylococci, and enterococci, respectively, were not essential for the flavor attributes of the cheeses. The culture results provide initial insight with regard to the presumptive bacterial species present in the cheeses but further analysis is required because it has been reported that some of these media are not very selective (Ampe et al., 1999; Randazzo et al., 2002; Ercolini et al., 2003). In this report, bacterial isolates recovered from the Chihuahua cheeses were further analyzed by $16 \mathrm{~S}$ rRNA gene sequence analysis to more accurately identify the species present. This method has been used successfully to characterize the bacterial species present in Queso Fresco obtained from Mexico (Renye et al., 2008).

Samples of 10 Chihuahua cheeses made with either raw (samples A-D, F, G, J) or pasteurized (L, M, P) milk were obtained from different commercial cheese plants in the state of Chihuahua, Mexico. The cheeses were obtained within $3 \mathrm{~d}$ of manufacture, packed in large coolers with ice packs, and shipped overnight to the Eastern Regional Research Center, Wyndmoor, Pennsylvania (Van Hekken et al., 2006). Bacterial isolates were initially characterized by growth on selective agar media (Bricker et al., 2005). Ten representative colonies from each selective media where chosen for $16 \mathrm{~S}$ rRNA gene sequence analysis. Isolates from VRB (EM Science, Gibbstown, NJ), Fluorocult VRB (FVRB; EM Science), BP (Difco Laboratories, Detroit, MI), and plate count agar (Oxoid, Basingstoke, UK) were grown in brain heart infusion broth (Difco); isolates from M17 (Difco) and KEA (EM Science) agar were grown in M17 broth (Difco); and isolates from de Man, Rogosa, and Sharpe (MRS; Difco) and MRS containing 100 $\mu \mathrm{g} / \mathrm{mL}$ of vancomycin (MRSV) agars were grown in MRS broth (Difco). Broth cultures were grown overnight at the same temperatures used for the initial agar incubations (Bricker et al., 2005).
Molecular identification of bacterial isolates recovered from the Chihuahua cheeses was determined as described previously (Renye et al., 2008) Briefly, genomic DNA was isolated using the Prepman Ultra DNA isolation reagent as suggested by the manufacturer (Applied Biosystems, Foster City, CA), and used as template for PCR amplification of the 16S rRNA gene $(\sim 1.5$ $\mathrm{kb})$ with the eubacterial oligonucleotide primers EubA and EubB (Cottrell and Kirchman, 2000). Nucleic acid sequencing of the 16S rRNA gene was performed using an ABI PRISM 3730 DNA analyzer (Perkin-Elmer, Wellesley, MA) with ABI PRISM Big Dye terminator cycle sequencing reagent and oligonucleotide primers EubA and EubB. Obtained sequences were analyzed using Sequencher 4.2 (Gene Codes Corp., Ann Arbor, $\mathrm{MI}$ ) and contained all 9 variable regions of the $16 \mathrm{~S}$ rRNA gene. Speciation was determined based on nucleic acid sequence comparison with available sequences in GenBank using the National Center for Biotechnology Information BLASTN search program (www.ncbi.nlm. nih.gov/BLAST/).

The EubA and EubB oligonucleotides were selected for 16S rRNA gene amplification because they have been shown to accurately identify the members of a marine bacterioplankton community (Cottrell and Kirchman, 2000) as well bacterial species found in Queso Fresco obtained directly from Mexican producers (Renye et al., 2008). The results obtained from $16 \mathrm{~S}$ rRNA gene sequence analysis confirmed that some of the agar media used for isolation of bacteria from the 10 Chihuahua cheese samples were not very selective (Tables 1 and 2). M17 medium was used to select for the growth of streptococcal species and, as expected, streptococci, lactococci, and enterococci were all isolated on the medium. In addition, M17 medium was able to support the growth of lactobacilli, leuconostoc species, Kocuria kristinae (98\% identity with AF501368), Corynebacterium mucifaciens (99\% identity with AF537599), and Cellulosimicrobium cellulans (99\% identity with AY501363). The MRS medium was used to select for growth of lactobacilli but it also supported the growth of streptococci, lactococci, enterococci, pediococci, leuconostocs, and pseudomonads. The MRSV agar was more selective, with isolates identified as lactobacilli or leuconostoc species, which are targeted with this medium. The most selective media were KEA and VRB, which allowed only for the growth of enterococci and coliforms, respectively. These results demonstrate the need for further molecular characterization when trying to understand the bacterial community within Chihuahua cheeses.

Table 1 lists the bacterial isolates that may have contributed to the production of the Chihuahua cheeses being studied. Semi-hard, Hispanic-style cheeses rely on 
Table 1. Bacterial species that may contribute to the production of Chihuahua cheeses

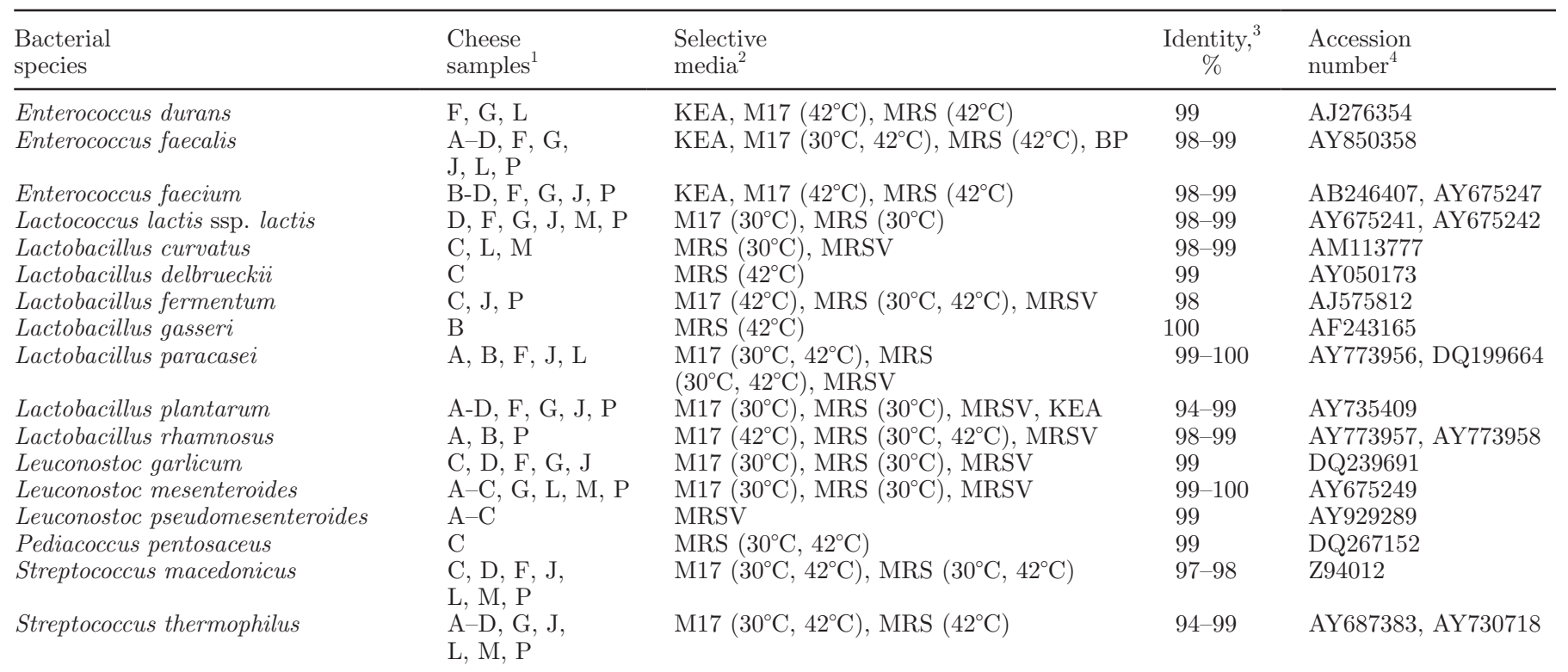

\footnotetext{
${ }^{1}$ Samples A, B, C, D, F, G, and J are from raw milk, and samples L, M, and P are from pasteurized milk; sample labels correspond to those in Van Hekken et al. (2006).

${ }^{2} \mathrm{KEA}=$ kanamycin esculin azide; MRS = de Man, Rogosa, and Sharpe; BP = Baird-Parker agar supplemented with egg yolk tellurite; MRSV $=$ MRS containing $100 \mu \mathrm{g} / \mathrm{mL}$ of vancomycin.

${ }^{3}$ Percentage identity of closest related species in GenBank.

${ }^{4}$ Accession number of the closest related species in GenBank.
}

lactic acid bacteria (LAB) for acidification of the milk before the addition of rennet. In this study, 2 strong acidifying bacterial species were identified: Lactococcus lactis ssp. lactis and Streptococcus thermophilus. Lactococcus lactis ssp. lactis is a common starter culture used for the production of aged Cheddar cheeses (Bissonnette et al., 2000), and Strep. thermophilus is used in the production of Swiss and Italian-style cheeses
(Rosenthal, 1991). Streptococcus thermophilus was isolated from 6 of 7 RM cheeses and from all 3 PM cheeses analyzed, suggesting that it is a necessary component of the starter culture required for the production of Chihuahua cheese. Lactococcus lactis ssp. lactis was less prevalent, being isolated from $4 \mathrm{RM}$ cheeses and $2 \mathrm{PM}$ cheeses. A direct-set starter culture containing Strep. thermophilus, Lc. lactis ssp. lactis, and Lc. lactis ssp.

Table 2. Potential pathogens and spoilage bacterial species identified in Chihuahua cheeses

\begin{tabular}{|c|c|c|c|c|}
\hline $\begin{array}{l}\text { Bacterial } \\
\text { species }\end{array}$ & $\begin{array}{l}\text { Cheese } \\
\text { samples }{ }^{1}\end{array}$ & $\begin{array}{l}\text { Selective } \\
\text { media }^{2}\end{array}$ & $\begin{array}{c}\text { Identity }^{3}{ }^{3} \\
\%\end{array}$ & $\begin{array}{l}\text { Accession } \\
\text { number }\end{array}$ \\
\hline Enterococcus gallinarum & $\mathrm{B}-\mathrm{D}, \mathrm{F}$ & $\operatorname{M} 17\left(42^{\circ} \mathrm{C}\right)$, KEA & 98 & AF277567 \\
\hline Enterococcus casseliflavus & $\mathrm{G}$ & $\mathrm{KEA}$ & 99 & DQ223887 \\
\hline Klebsiella ornithinolytica & $\mathrm{F}$ & $\mathrm{BP}$ & 91 & U78182 \\
\hline Lactococcus garvieae & $\mathrm{A}-\mathrm{D}, \mathrm{G}, \mathrm{J}, \mathrm{L}$ & $\operatorname{M} 17\left(30^{\circ} \mathrm{C}, 42^{\circ} \mathrm{C}\right), \operatorname{MRS}\left(30^{\circ} \mathrm{C}\right)$ & $96-100$ & AY699289 \\
\hline Lactococcus MKRL19 & $F, G$ & $\operatorname{M} 17\left(30^{\circ} \mathrm{C}\right)$ & 99 & AY762104 \\
\hline Staphylococcus epidermidis & B, L & $\mathrm{BP}$ & $88-98$ & AF397060, AJ717377 \\
\hline Staphylococcus chromogenes & $\mathrm{G}$ & $\mathrm{BP}$ & 99 & D83360 \\
\hline Streptococcus bovis & C. D. F & $\operatorname{M} 17\left(30^{\circ} \mathrm{C}, 42^{\circ} \mathrm{C}\right), \operatorname{MRS}\left(42^{\circ} \mathrm{C}\right)$ & $97-98$ & AF429766 \\
\hline
\end{tabular}

${ }^{1}$ Samples A, B, C, D, F, G, and J are from raw milk, and samples L, M, and P are from pasteurized milk; sample labels correspond to those in Van Hekken et al. (2006).

${ }^{2} \mathrm{KEA}=$ kanamycin esculin azide; FVRB = Fluorocult violet red bile; BP = Baird-Parker agar supplemented with egg yolk tellurite; MRS = de Man, Rogosa, and Sharpe.

${ }^{3}$ Percentage identity of closest related species in GenBank.

${ }^{4}$ Accession number of the closest related species in GenBank. 
cremoris is available for the production of Chihuahuastyle cheese (Danlac, Alberta, Canada); however, the Mexican cheeses containing both Strep. thermophilus and Lc. lactis ssp. lactis (samples D, G, J, M, and P) did not have identical sensory profiles, and cheese $G$ was chosen, in an informal flavor ranking, to possess the "ideal" Chihuahua flavor (Van Hekken et al., 2006). These results suggest that additional nonstarter LAB (NSLAB) may play an essential role in the flavor development of the cheese. Although Lc. lactis ssp. cremoris was included in a commercial starter culture for a similar style of cheese, it was not identified in this study, possibly due to its sensitivity to the cooking temperatures $\left(38-43^{\circ} \mathrm{C}\right)$ used during cheese production (Tunick et al., 2008).

Lactobacillus species are NSLAB associated with flavor development in Cheddar cheese as it ripens (Swearingen et al., 2001). Lactobacilli were isolated from all the cheeses analyzed, although a single species common to all samples was not identified (Table 1). The most prevalent species identified was Lactobacillus plantarum, which was present in all $7 \mathrm{RM}$ samples but was only present in $1 \mathrm{PM}$ sample $(\mathrm{P})$. The remaining $2 \mathrm{PM}$ samples ( $\mathrm{L}$ and $\mathrm{M}$ ) were shown to contain Lactobacillus curvatus, which is more commonly associated with formation of calcium lactate crystals instead of flavor development (Agarwal et al., 2006).

Enterococci are often isolated from raw milk cheeses and have been discussed as possible adjunct cultures due to their proteolytic and lipolytic activities; however, their potential as human pathogens has limited their use in cheese production (Foulquié Moreno et al., 2006). With regard to Mexican cheeses, it has been suggested that Enterococcus faecium may be required for the production of traditional Mexican Queso Fresco (Torres-Llanez et al., 2006; Renye et al., 2008). In this study, Enterococcus faecalis was identified in all RM samples and 2 PM samples. The PM samples L and P also contained Enterococcus durans and Ent. faecium, respectively. The PM sample $\mathrm{M}$ was the only cheese in which enterococcal species were not identified.

Leuconostoc mesenteroides and Streptococcus macedonicus were both identified in $4 \mathrm{RM}$ samples and all 3 PM samples. Leuconostoc mesenteroides has been suggested as an adjunct culture leading to the diacetyl flavor attribute found in cheeses because of the species' ability to metabolize citrate (Rondinini and Bortolussi, 1994). Streptococcus macedonicus was originally isolated from Greek Kasseri cheese and may serve as an adjunct culture because of its peptidolytic activity and ability to hydrolyze milk fat (Georgalaki et al., 2000).

Table 2 lists the bacterial species identified that may act as potential pathogens or food spoilage organisms. Bacterial isolates were recovered from all RM cheeses and from 1 PM sample on FVRB agar, selecting for fecal coliforms. Sequence analysis of an approximately 800 -bp region of the $16 \mathrm{~S}$ rRNA gene, containing variable regions 4 to 8 , could not clearly determine if these isolates were Escherichia coli or Shigella boydii. However, independent analysis by Silliker Laboratories (Homewood, IL) showed that they were not $E$. coli O157:H7. The potential staphylococcal pathogens Staph. aureus and Staph. epidermidis were identified in 8 and 2 cheese samples, respectively; and the bovine pathogen Staphylococcus chromogenes was identified in RM sample G. Other potential human pathogens included Enterococcus gallinarum, Enterococcus casseliflavus, Lactococcus garvieae, and Streptococcus bovis isolated from $4,1,7$, and 3 cheese samples, respectively. Lactococcus MKRL19 and Pseudomonas putida were also isolated from 2 and $3 \mathrm{RM}$ cheeses, respectively, and have both been reported to act as spoilage organisms in food environments (Morales et al., 2005; Vihavainen et al., 2007).

In conclusion, this work suggests that Lc. lactis ssp. lactis and Strep. thermophilus should be included as part of a starter culture for the production of Chihuahua cheese. In addition, Leu. mesenteroides, Lactobacillus plantarum, Ent. faecium, Ent. faecalis, and Ent. durans were all identified in cheese $G$, suggesting that they may serve as NSLAB for development of the "ideal" flavor associated with traditional Chihuahua cheese. The results presented in this study provide insight to the bacterial species that may be used to produce a Chihuahua cheese using pasteurized milk while maintaining the traditional sensory profile of the traditional raw milk variety.

\section{ACKNOWLEDGMENTS}

We thank S. Iandola and D. Needleman (Eastern Regional Research Center, Wyndmoor, PA) for technical assistance and nucleic acid sequencing.

\section{REFERENCES}

Agarwal, S., K. Sharma, B. G. Swanson, G. U. Yuksel, and S. Clark. 2006. Nonstarter lactic acid bacteria biofilms and calcium lactate crystals in Cheddar cheese. J. Dairy Sci. 89:1452-1466.

Ampe, F., N. Ben Omar, C. Moizan, C. Wacher, and J. P. Guyot. 1999. Polyphasic study of the spatial distribution of microorganisms in Mexican pozol, a fermented maize dough, demonstrates the need for cultivation-independent methods to investigate traditional fermentations. Appl. Environ. Microbiol. 65:5464-5473.

Bissonnette, F., S. Labrie, H. Deveau, M. Lamourex, and S. Moineau 2000. Characterization of mesophilic mixed starter cultures used for the manufacture of aged Cheddar cheese. J. Dairy Sci. 83:620627.

Bricker, A. L., D. L. Van Hekken, V. M. Guerrero, and A. A. Gardea. 2005. Microflora isolated from Mexican Mennonite-style cheeses. Food Prot. Trends 25:637-640.

Code of Federal Regulations. 2004. Cheeses and related cheese products. Code of Federal Regulations. Title 21, Vol. 2, Part 
133. http://www.accessdata.fda.gov/scripts/cdrh/cfdocs/cfcfr/ CFRSearch.cfm?CFRPart $=133$.

Cottrell, M. T., and D. L. Kirchman. 2000. Community of marine bacterioplankton determined by $16 \mathrm{~S}$ rRNA gene clone libraries and fluorescence in situ hybridization. Appl. Environ. Microbiol. 66:5116-5122.

Diaz-Cinco, M. E., O. Fraijo, P. Grajeda, J. Lozano-Taylor, and E. Gonzalez de Mejía. 1992. Microbial and chemical analysis of Chihuahua cheese and relationship to histamine and tyramine. J. Food Sci. 57:355-356., 365.

Ercolini, D., P. J. Hill, and C. E. R. Dodd. 2003. Bacterial community structure and location in Stilton cheese. Appl. Environ. Microbiol. 69:3540-3548.

Foulquié Moreno, M. R., P. Sarantinopoulos, E. Tsakalidou, and L. De Vuyst. 2006. The role and application of enterococci in food and health. Int. J. Food Microbiol. 106:1-24.

Georgalaki, M. D., P. Sarantinopoulos, E. S. Ferreira, L. De Vuyst, G. Kalantzopoulos, and E. Tsakalidou. 2000. Biochemical properties of Streptococcus macedonicus strains isolated from Greek Kasseri cheese. J. Appl. Microbiol. 88:817-825.

Kosikowski, F. V., and V. V. Mistry. 1997. Page 266 in Cheese and Fermented Milk Foods. Vol. 1. 3rd ed. F. V. Kosikowski LLC, Westport, CT.

Morales, P., E. Fernandez-Garcia, and M. Nunez. 2005. Volatile compounds produced in cheese by Pseudomonas strains of dairy origin belonging to six different species. J. Agric. Food Chem. 53:68356843.

Randazzo, C. L., S. Torriani, A. D. L. Akkermans, W. M. De Vos, and E. E. Vaughan. 2002. Diversity, dynamics and activity of bacterial communities during production of an artisanal Sicilian cheese as evaluated by $16 \mathrm{~S}$ rRNA analysis. Appl. Environ. Microbiol. 68:1882-1892.

Renye, J. A., Jr., G. A. Somkuti, B. Vallejo-Cordoba, D. L. Van Hekken, and A. F. Gonzalez-Cordova. 2008. Characterization of the microflora isolated from queso fresco made from raw and pasteurized milk. J. Food Saf. 28:59-75.

Rondinini, G., and G. Bortolussi. 1994. Importance of Leuconostoc in Montasio cheesemaking and setting up of a quantification rapid method in milk. Ann. Microbiol. Enzimol. 44:277-281.
Rosenthal, I. 1991. Conversion of milk to products. Chapter 4 in Milk and Dairy Products: Properties and Processing. VCH, NY.

Saltijeral, J. A., V. B. Alvarez, and B. Garcia. 1999. Presence of Listeria in Mexican cheeses. J. Food Saf. 19:241-247.

Secretaria de Salud-Mexico. 1994. Quesos Madurados. Norma Oficial Mexicana 121-SSA1. Secretaria de Salud, Mexico City, Mexico.

Solano-López, C., and H. Hernández-Sánchez. 2000. Behaviour of Listeria monocytogenes during the manufacture and ripening of Manchego and Chihuahua Mexican cheeses. Int. J. Food Microbiol. 62:149-153.

Swearingen, P. A., D. J. O'Sullivan, and J. J. Warthesen. 2001. Isolation, characterization and influence of native, non-starter lactic acid bacteria on Cheddar cheese quality. J. Dairy Sci. 84:50-59.

Torres-Llanez, M. J., B. Vallejo-Cordoba, M. E. Diaz-Cinco, M. A. Mazorra-Manzano, and A. F. Gonzalez-Cordova. 2006. Characterization of the natural microflora of artisanal Mexican Fresco cheese. Food Contr. 17:683-690.

Tunick, M. H., D. L. Van Hekken, F. J. Molina-Corral, P. M. Tomasula, J. E. Call, J. B. Luchansky, and A. A. Gardea. 2008. Chihuahua cheese: Manufacturing procedures, composition, protein profiles, and microbiology. Int. J. Dairy Technol. 61:62-69.

Van Hekken, D. L., M. A. Drake, F. J. Molina-Corral, V. M. Guerrero Prieto, and A. A. Gardea. 2006. Mexican Chihuahua cheese: Sensory profiles of young cheese. J. Dairy Sci. 89:3729-3738.

Van Hekken, D. L., and N. Farkye. 2003. Hispanic cheeses. The quest for queso. Food Technol. 57:32-38.

Van Hekken, D. L., M. H. Tunick, P. M. Tomasula, F. J. Molina-Corral, and A. A. Gardea. 2007. Mexican Queso Chihuahua: Rheology of fresh cheese. Int. J. Dairy Technol. 60:5-12.

Vihavainen, E., H.-S. Lundstrom, T. Susiluoto, J. Koort, L. Paulin, P. Auvinen, and K. J. Bjorkroth. 2007. Role of broiler carcasses and processing plant air in contamination of modified-atmospherepackaged broiler products with psychrotrophic lactic acid bacteria. Appl. Environ. Microbiol. 73:1136-1145. 